\title{
Eskişehir'den Üç Yeni Meter Tetraprosopos Adağı
}

\author{
Three New Dedications to Meter Tetraprosopos from Eskişehir
}

\section{N. Eda AKYÜREK ŞAHİN*}

Özet: Makalede Eskişehir'de (Dorylaion teritoryumu) çeşitli yerlerde bulunmuş (Harita) ve bugün Eskişehir Müzesi'nde korunmakta olan üç eser (Fig. 1-3) tanıtılmaktadır. Her üç eser de adak taşı olup Meter

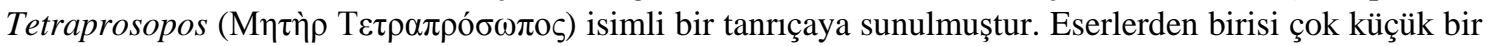
altardır (Fig. 1 a-b) ve üzerinde Eski Yunanca adak yazıtı vardır. Eserin akroterleri arasına ise tanrıçanın dörtlü figürü kabartma olarak işlenmiştir. İkinci eser (Fig. 2 a-d) alt kısmı kırılmış dörtlü bir heykelciktir. Üçüncü eser (Fig. 3 a-d) ise, üzerinde tanrıçanın sadece dört başından oluşan bir kabartma bulunan küçük bir adak levhasıdır. 2. ve 3. eserlerin yazıtı yoktur. Eserde tanrıçanın belirli bir ikonografide betimlendiği görülmektedir. Tanrıça yan yana bitişik duran ve khiton giymiş dört kadın biçiminde betimlenmiş olup hepsinin de başında stephane tacı bulunmaktadır. Altar üzerindeki figürler ellerinde girland taşımaktadır. Kırık olan ikinci heykelcikte de figürler ellerinde girland taşıyor olmalıdır. Phrygia ve Galatia bölgelerinde yazıtlar aracıllğı ile tanınan "Meter Tetraprosopos" (Dört yüzlü Meter) isimli bir tanrıça vardır. Söz konusu yazıtların üzerinde herhangi bir betim yoktur. Ancak, yine Phrygia Bölgesi'nde dört vücutlu ve dört yüzlü bir tanrıça ikonografisinde olan bazı yazıtsız adaklar da ele geçmiştir. Kanaatimce, yazıtlarda adı geçen "Dört Yüzlü" tanrıça ile bu şekilde betimlenen figürlerde aynı tanrıça kastedilmektedir. Afyon Müzesi'nde korunan ve yine Meter Tetraprosopos'u betimlediğini düşündüğüm iki eser hakkındaki makalemde bu konuya değinilmiş ve kültle ilgili bilinen tüm belgeler toplanmıştır (Akyürek Şahin 2010).

Anahtar Sözcükler: Meter Tetraprosopos, Phrygia, Dorylaion, Eskişehir Müzesi, Adak yazıtı

Abstract: In this article, three carved works in stone (Figs. 1-3) found in a variety of areas in Eskişehir (Map) (within the territory of Dorylaion) and preserved in the archaeological museum of Eskişehir are introduced.

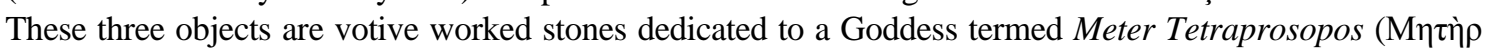

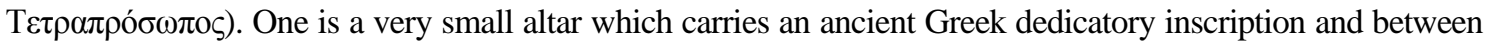
the acroteria there is the quadruple figure of the goddess recorded in relief. The second monument (Figs 2 a-d) is a carving of a quadruple figurine, the lower part of which is lost. The third object (Figs. 3 a-d) is a small dedication, a relief carving consisting of only the four heads of the goddess. There are no inscriptions on the second and third objects. It is observed that this goddess is depicted possessing a distinct and distinguishing iconography. The goddess is depicted through the portrayal of four women standing side by side, all wearing chitons and having a stephane crown upon their heads. The figures on the altar carry garlands in their hands. The figures on the second, broken figurine would also have carried garlands in their hands. There is a Goddess termed "Meter Tetraprosopos" (the four-faced Meter) known from inscriptions from the regions of Galatia and Phrygia but there are however, no depictions of the Goddess recorded with these inscriptions. However, some uninscribed votive stones carrying this iconography of the Goddess with four faces and four bodies are also known from Phrygia. I propose that the four-headed Goddess mentioned in these inscriptions is to be identified with the Goddess depicted in this manner. In my article on two works preserved in Afyon Museum and which, in my opinion also portrays Meter Tetraprosopos, published prviously, and the documents concerning this cult have also been compiled (see: Akyürek Şahin 2010).

Keywords: Meter Tetraprosopos, Phrygia, Dorylaion, Eskişehir Museum, Dedication

* Doç. Dr., Akdeniz Üniversitesi, Edebiyat Fakültesi, Eskiçağ Dilleri ve Kültürleri Bölümü, Antalya, edasahin@akdeniz.edu.tr 
Meter Anadolu'da birçok yan isimle (epitheton) tapınım görmüş bir tanrıçadır (Vermaseren, 1987; Lane, 1996). Bu yan isimlerden bir tanesi de "Tetraprosopos" yani "dört yüzlü/dört çehreli" olarak çevirebileceğimiz bir isimdir (Vermaseren, 1987, 20-21, no. 48). Phrygia ve Galatia bölgelerinde bulunmuş birkaç yazıtta (Galatia [bir yazıt]: Anderson, 1897-1898, 61 = Anderson, 1899, 303, no. 237 = Roscher, 1916-1924, col. 402 = Schwenn, 1922, col. 2297 = Robert, 1946, Hellenica II, 153 = Vermaseren, 1987, 20-21, no. 48; Phrygia [iki yazıt]: Cox, \& Cameron, 1937, no. 101; Macpherson, 1954, no. 4 = Robert, 1946, Hellenica II, 153 = Robert, \& Robert 1956, no.

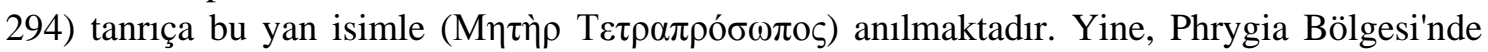
ele geçen ve üzerinde yazıt bulunmayan birkaç küçük adağın dört kadın figüründen oluşan bir ikonografiye sahip olduğu görülmektedir (Levick, \& Mitchell, 1993, no. 53 = Akyürek Şahin, 2010, no. 3; Akyürek Şahin, 2010, no. 1-2). Dörtlü betimlerdeki figürlerin, başlarında taşıdıkları "stephane tacı" nedeniyle bir tanrıçayı betimledikleri kesindir. Betimlerde figürler ellerinde daima girland taşımaktadır. Figürlerin bir sütun çevresinde sırt sırta vermiş şekilde durdukları anlaşılmaktadır. Bazı eserlerde figürlerin yan yana bitişik şekilde betimlenmiş oldukları görülmektedir. Bu betimleniş şekli ile de yine bir sütun çevresinde sırt sırta duruş kastedilmektedir. Dört figürle betimlenen bu tanrıçanın ise, seneler önce MAMA V'in yazarlarının da dile getirdiği gibi (Cox, \& Cameron, 1937, 54 no. 101), yazıtlarda adı geçen "Meter Tetraprosopos" olma olasılığı kanaatimce oldukça yüksektir. Ancak, bu tür bir betim taşıyan ve üzerindeki yazıtta açıkça bu tanrıçanın adının okunduğu bir adak taşı henüz ele geçmemiştir. Bu kültle ilgili eserler henüz oldukça az sayıdadır, ancak araştırmalar ilerledikçe, daha fazla eserin bulunacağı ya da farkedileceği kesindir (Meter Tetraprosopos ile ilgili olabilecek eserler için bkz. Ramsay, 1918, 152-168; Calder, \& Cormack, 1962, no. 374). Bu makalede tanıtılan üç yeni eser, buluntu yerleri dışında fazla yeni bir bilgi sunmasa da kültle ilgili belgelerin sayısını artırmaktadır.

Dörtlü biçimde ve sırt sırta (ya da yan yana) betimlenme ikonografisi aslında Tanrıça Hekate'ye aittir. Hekate Phrygia'da oldukça yaygın biçimde tapınım görmüştür ve tanrıçanın birçok betimi ele geçmiştir (Akyürek Şahin, 2006a; 2007, no: 67-69). Meter Tetraprosopos betimi için Hekate İkonografisi'nin kullanıldığı anlaşılmaktadır. Bu tanrıçayı Hekate'den ayıran en kesin ikonografik özellikler ise, dörtlü betimleniş ve figürlerin ellerinde girland tutmalarıdır.

Bugün Eskişehir Arkeoloji Müzesi'nde bulunan ve burada tanıtılan üç yeni eser de (Fig. 1-3) hiç kuşkusuz Meter Tetraprosopos'a sunulmuştur ve bu tanrıçayı betimlemektedir. Eserlerden biri, üzerinde Eski Yunanca adak yazıtı bulunan çok küçük bir altardır (Fig. 1 a-b). Altarın akroterleri arasına tanrıçanın dörtlü figürü kabartma olarak işlenmiştir. İkinci eser (Fig. 2 a-d) alt kısmı kırılmış yazıtsız dörtlü bir heykelciktir. Üçüncü eser (Fig. 3 a-d) ise, üzerinde sadece tanrıçanın dört başından oluşan kabartma bulunan yazıtsız küçük bir adak levhasıdır. Eserlerin betimlenişi tanrıçanın bilinen ikonografisine uymaktadır. Altarcık üzerindeki figürler ellerinde girland taşımaktadır. Kırık olan ikinci eserde de figürler ellerinde girland taşıyor olmalıdır.

Kültle ilgili eserlere bakıldığında buluntuların bugüne kadar daha çok Eskişehir bölgesinden geldiği görülmektedir. Burada tanıtılan üç yeni adak dışında, daha önceden bilinen iki adak da (Cox, \& Cameron, 1937, no. 101; Macpherson, 1954, no. 4) hesaba katılırsa beş adakla Eskişehir bölgesi kült açısından önemli bir bölgedir. Bu kültün ortaya çıkış merkezi antikçağda olasılıkla Dorylaion teritoryumudur. İleride ele geçecek yeni eserler konunun netleşmesini sağlayacaktır.

Modern literatürde hakkında neredeyse hiç bilgi bulunmayan bu kültün özü hakkında, konu ile ilgili daha önceki bir makalemde bilgi verilmiştir (Akyürek Şahin, 2010, 29-30). J. G. C. Anderson bu tanrıça ile döt mevsimi sembolize eden Kybele'nin anlaşılması gerektiğini belirtmiştir (Anderson, 1899, 303, no. 237). W. M. Ramsay ise dört yüzlü tanrıçanın dörtyolların kesiştiği yerleri sembolize ettiğini düşünmüş ve her bir yüzün bir yöne baktığı fikrini öne sürmüştür (Ramsay, 1918, 167-168). Bu tanrıçanın Phrygia Bölgesi'nde tapınım görmüş olması kültün büyük bir olasılıkla bereket ile de ilişkili olduğunu düşündürmektedir. Ancak henüz kültün asıl 
özü ve antikçağ insanının bu tanrıçaya tapınma amacı açık değildir. Kökeni olasılıkla çok daha eskiye giden bu kültle ilgili eserler genel olarak Roma İmparatorluk Dönemi'ne, İ.S. II. veya İ.S. III. yüzyıla tarihlenebilir.

\title{
ADAKLAR
}

\section{Küçük Altar (Fig. 1 a-b)}

Env. no.: A-242-67; Bul. Yeri: Envanter bilgisine göre Kadıkuyusu Köyü/Çifteler/Eskişehir; Malz.: Mermer; Yük.: 36 cm; Gen.: 23-24 cm; Kal.: 12 cm; Harf Yük.: yak. 2,1-1,5 cm.

Kalınlığı fazla olmayan küçük altar alttan ve üstten profilli işlenmiştir. Eserin başlık kısmını oluşturan üst profilinde ve ön yüzde her iki yanda bitkisel bezemeleri olan akroterler vardır. Akroterlerin arasına oldukça küçük boyda ve yan yana bitişik duran dört kadın figürü işlenmiştir. Kabartma biçimindeki figürler başlarında taç biçimli bir başlık olan "stephane" taşımakta ve her iki elleriyle birer girland tutmaktadır. Khiton giydikleri anlaşılan figürlerin başka ayrıntıları seçilememektedir. Altarın arka cephesi kaba işlenmiştir. Altarın üzerinde, üst profilin hemen altında iki satırlık Eski Yunanca bir yazıt okunmaktadır:

\author{
Палац Kapıк- $\quad$ Karikos'un oğlu Papas

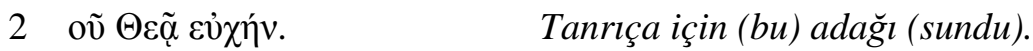

Papas ve Karikos Anadolu'da ama özellikle Phrygia Bölgesi'nde çok sık belgelenen erkek isimleridir. Papas ismi için bkz. Zgusta, 1964, 406 vd; Akyürek Şahin, 2006b, 56, no. 61 ve 76, no. 104; Drew-Bear, Thomas, \& Yıldızturan, 1999, 389. Karikos ismi için bkz. Zgusta, 1964, 215; Akyürek Şahin, 2006b, 28, no. 5; Drew-Bear, Thomas, \& Yıldızturan, 1999, 386.

Adağın sunulduğu tanrıçanın kim olduğu yazıtta açık değildir ve sadece "Tanrıça için" ifadesi geçmektedir. Ancak, altar üzerinde betimlenmiş dörtlü figür nedeniyle adağın sunulduğu tanrıçanın "Meter Tetraprosopos" olduğu kabul edilebilir.

\section{Küçük Adak Heykelciği (Fig. 2 a-d)}

Env. no.: A-197-67; Bul. Yeri: Battalgazi Tepesi/Seyitgazi/Eskişehir; Malz.: Beyaz mermer; Yük.: 18 cm; Gen.: 24,5 cm; Kal.: 5,5-7 cm.

Mermerden işlenmiş bu küçük heykelciğin alt kısmı kırık ve kayıptır. Düz durması amacıyla müzede alçıdan bir altlık üzerine oturtulmuştur. Heykelciğin kalınlığı az olup neredeyse bir kabartma izlenimi vermektedir. Phrygia Bölgesi'nde bazı eserlerin bu şekilde, fazla derinliğe sahip olmadan işlenmesi Geç Roma Dönemi için bilinen bir stil özelliğidir. Heykelcikte birbirinin neredeyse aynısı dört kadın figürü yan yana bitişik durmaktadır. Figürler bir orta sütun etrafında dizilmiş izlenimi vermektedir. Sütunun üzerinde uçları yukarı bakan dolgun bir hilal motifi vardır. Sağ dış taraftaki figürün başının üst kısmı kırıktır. Eserin üzerinde yer yer zedelenmeler görülmektedir. Her biri dalgalı saçlarının üzerinde stephane tacı taşımaktadır ve khiton giydikleri görülmektedir. Yüz hatları ayrıntılı değildir; bazı yüzler ise zarar görmüştür. Dış cephelerdeki figürlerin gövdeleri yan tarafa bakarken yüzleri cepheden verilmiştir. Yan bakan gövdeler, figürlerin orta sütun çevresinde durduklarını göstermek içindir. Buradaki figürlerle kastedilen, yine dört yüzlü tanrıça Meter Tetraprosopos olmalıdır. Büyük bir olasılıkla figürler elleriyle birer girland taşıyor olmalıydılar.

\section{Küçük Adak Levhası (Fig. 3 a-d)}

Env. no.: A-1-99; Bul. Yeri: Tam buluntu yeri bilinmiyor ancak Eskişehir bölgesinden getirilmiştir; Malz.: Beyaz mermer; Yük.: 25 cm; Gen.: 17-20 cm; Kal.: 5-6 cm. 
Küçük ve ince bir mermer levhanın işlenmesi ile oluşturulmuş adak taşının üst tarafı üçgen bir alınlığın sadece üst kısmı şeklinde işlenmiştir. Alınlığın hemen altında ise yan yana bitişik gibi duran dört kadın figürünün sadece başları resmedilmiştir. Her dört figür de başları üzerinde, ortasında ayrım olan birer stephane taşımaktadır. Figürlerin yüz hatları çok kaba işlenmiş olup ayrıntılar verilmemiştir. Boyunlarından alt kısmı işlenmeyen figürlerin hemen altında ise boş bir alan vardır. Kaba işlenen bu alan büyük bir olasılıkla bir adak yazıtı için ayrılmıştır. Eserin üzerinde yazıt olmaması adak olarak hiç sunulmamış (atölyede üretildikten sonra hiç satılmamış bir eser) olabileceğini de akla getirmektedir. Eserin arka cephesi işlenmeden kaba bırakılmıștır. Bu figürler yine Meter Tetraprosopos'u betimliyor olmalıdır.

\section{Yazarın Notu}

Başta epigrafik olmak üzere Eskişehir Müzesi'ndeki çeşitli çalışmalarım için izin veren Kültür Bakanlığı, Kültür Varlıkları ve Müzeler Genel Müdürlügü'ne teşekkür ederim. Makalede tanıtılan eserleri çalışmama izin veren Eskişehir Müzesi Müdürü Sayın Dursun Çağlar'a da içten teşekkür ediyorum. Ayrıca müze uzmanları sayın Gülsüm Baykal ile sayın M. Zeki Bürkük'e de çok teşekkür ederim. Müzedeki çalışmalarımda bana yardımcı olan meslektaşım Sayın Yrd. Doç. Dr. Fatih Onur ile araştırma görevlileri Hüseyin Uzunoğlu ve Erkan Taşdelen'e de ayrıca teşekkürlerimi sunarım.

Eskişehir Müzesi'nin yeni yazıtları üzerindeki epigrafik çalışmalarım sürecektir ve kaydettiğimiz eserlerin bazıları yayıma hazırlanmaktadır.

Bu yayındaki harita dışındaki fotoğrafların tamamı yazar tarafından çekilmiştir. 


\section{KAYNAKÇA}

Akyürek Şahin, N. E. (2006a). “Anadolu Hekate Korpusu ve Çeşitli Müzelerde Hekate Eserleri Üzerinde Çalışmalar. Bir Ön Rapor”. Arkeoloji ve Sanat, 121, 59-67.

Akyürek Şahin, N. E. (2006b). Yazıdere Zeus Kutsal Alanı. Phrygia'da Yerel Bir Tapınım Merkezi. İstanbul. Ege Yayınları.

Akyürek Şahin, N. E. (2007). "Neue Weihungen aus dem Museum von Afyon”. Gephyra, 4, 59-115.

Akyürek Şahin, N. E. (2010). "Meter Tetraprosopos İçin Phrygia'dan İki Yazıtsız Belge”. Arkeoloji ve Sanat, 133, 27-38.

Anderson, J. G. C. (1897-1898). "Exploration in Asia Minor During 1898: First Report”. BSA, IV, 49-78.

Anderson, J. G. C. (1899). “Exploration in Galatia cis Halym. II”. JHS, 19, 280-318.

Calder, W. M., \& Cormack, J. M. R. et alii (1962). Monuments from Lycaonia, The Pisido-Phrygian Borderland, Aphrodisias. MAMA, VIII. Manchester.

Cox, C. W. M., \& Cameron, A. (1937) Monuments from Dorylaeum and Nacolea. MAMA, V. Manchester.

Drew-Bear, Th., Thomas, Ch. M., \& Yıldızturan, M. (1999). Phrygian Votive Steles. The Museum of Anatolian Civilizations. Ankara.

Lane, E. N. (ed.) (1996). Cybele, Attis and Related Cults. Esseys in Memory of M. J. Vermaseren. Leiden, New York, Köln. EPRO 131.

Levick, B., \& Mitchell, St. et alii (eds.) (1993). Monuments from Appia and the Upper Tembris Valley, Cotiaeum, Cadi, Synaus, Ancyra Sidera and Tiberiopolis. MAMA, X. London.

Macpherson, I. W. (1954). "Inscriptions from Eskişehir and District". BSA, 49, 11-16.

Ramsay, W. M. (1918). “The Utilisation of Old Epigraphic Copies”. JHS, 38, 124-192.

Robert, J. - L. Robert (1938-1985). Bulletin Épigraphique, Revue des Études Grecques. Paris.

Robert, L. (1942-1965). Hellenica. Recueil d'Épigraphie, de Numismatique et d'Antiquités Grecques IXIII. Paris.

Roscher, W. H. (1916-1924). Roschers Ausführliches Lexikon der griechischen Mythologie. Leipzig.

Schwenn, F. (1922). s.v. “Kybele”. RE XI 2, col. 2250-2298.

Vermaseren, M. J. (1987). Corpus Cultus Cybelae Attidisque (CCCA) I. Asia Minor. Leiden vd. EPRO $50,1$.

Zgusta, L. (1964). Kleinasiatische Personennamen. Prag. 


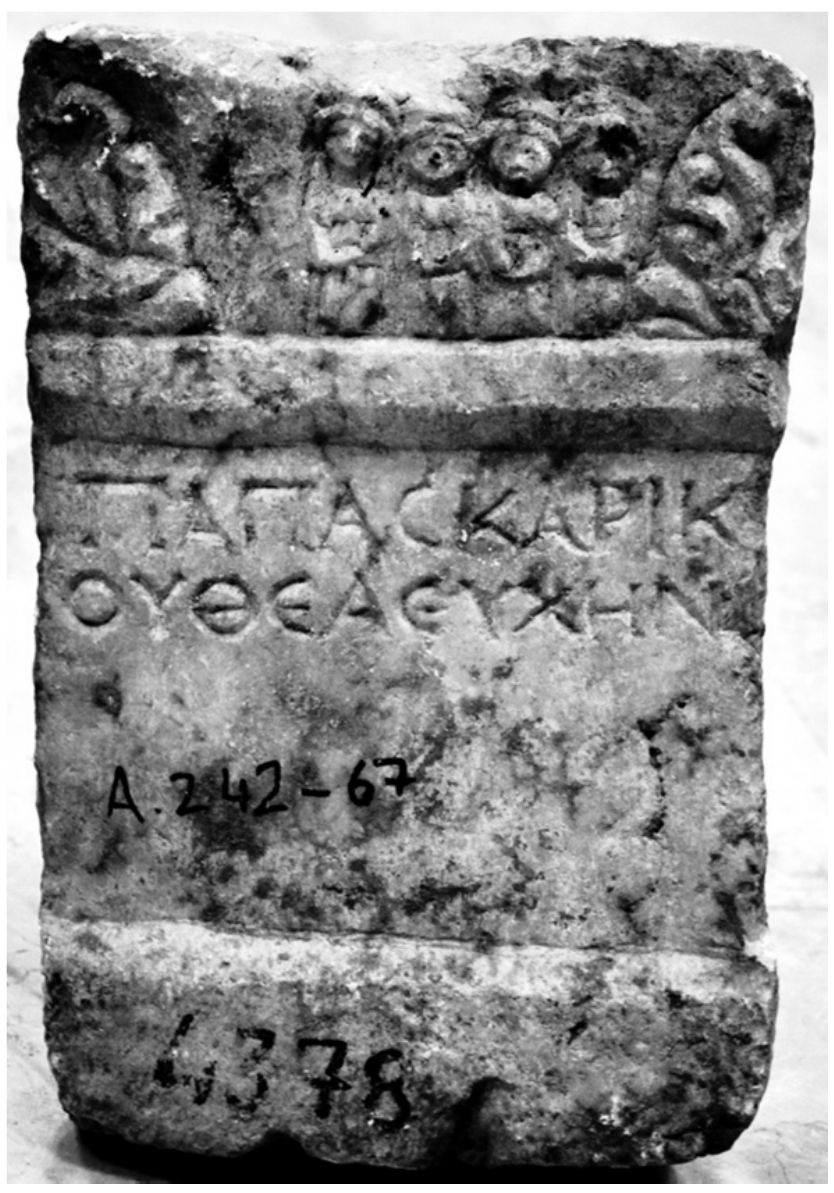

Figür 1 a

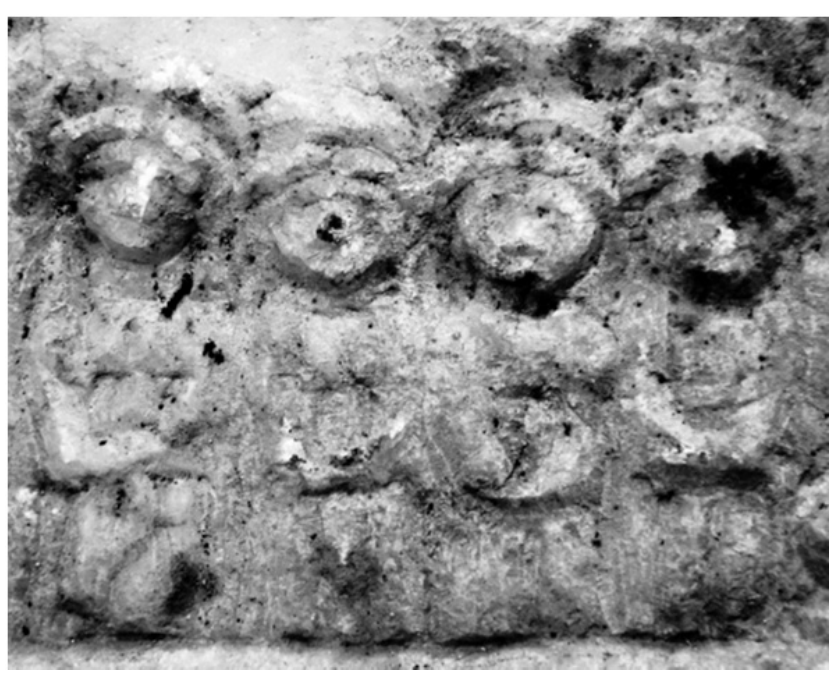

Figür 1 b 


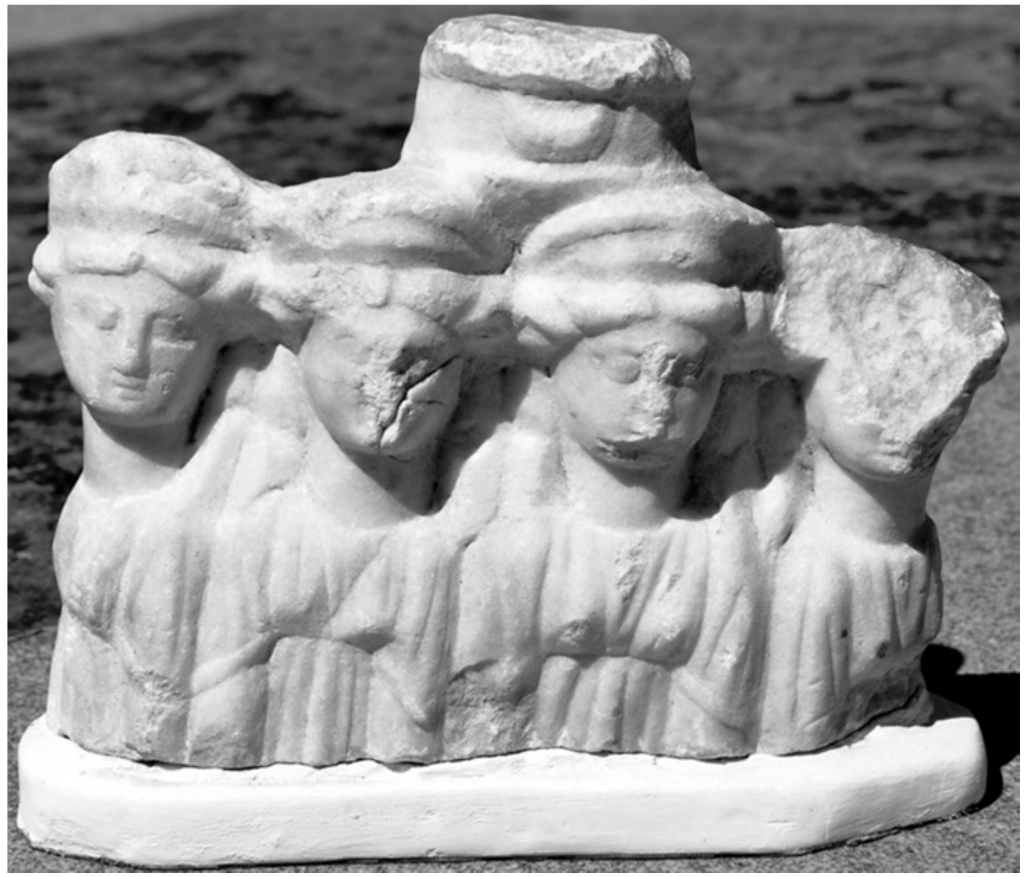

Figür 2 a

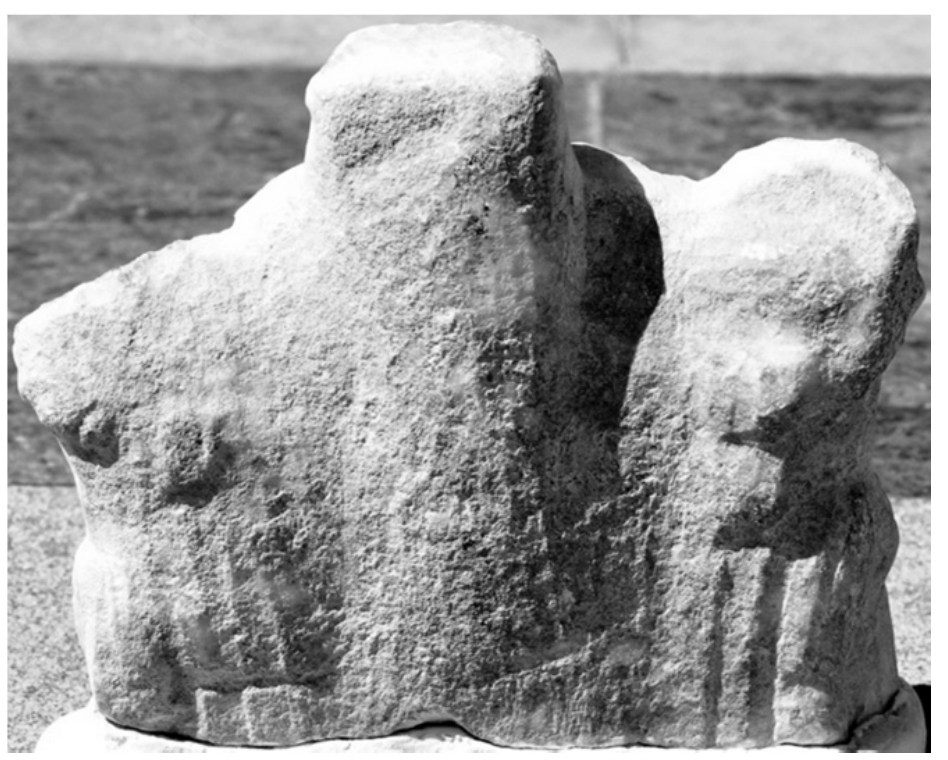

Figür 2 c

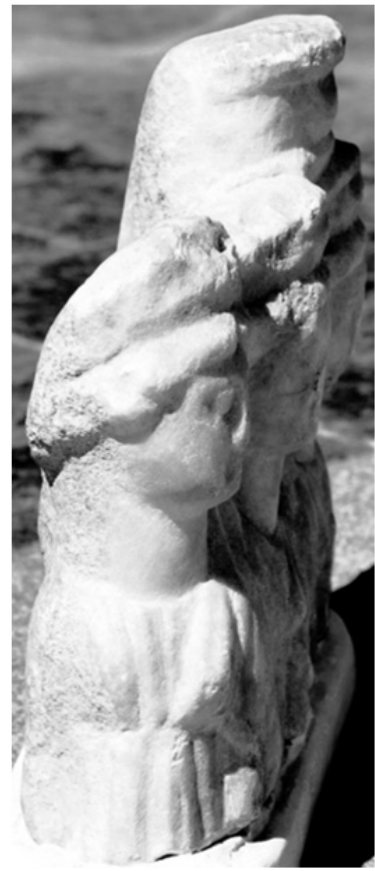

Figür 2 b

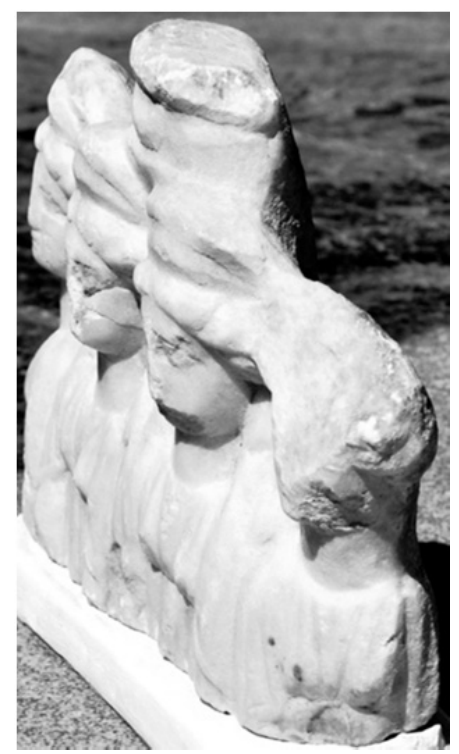

Figür $2 \mathrm{~d}$ 


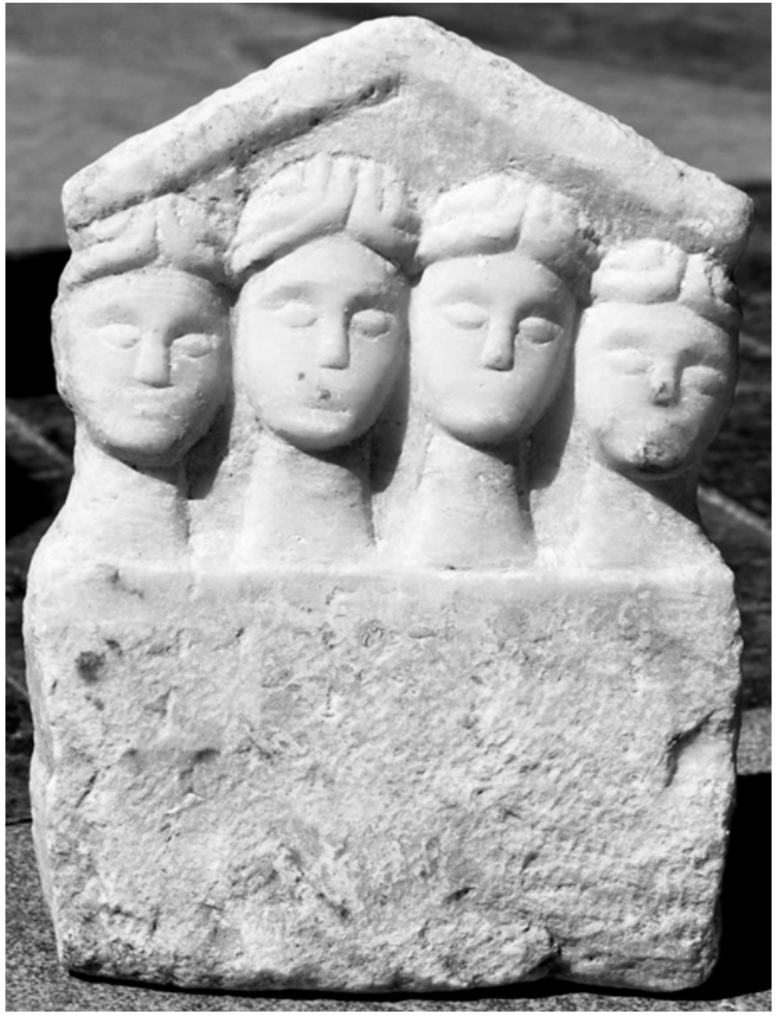

Figür a

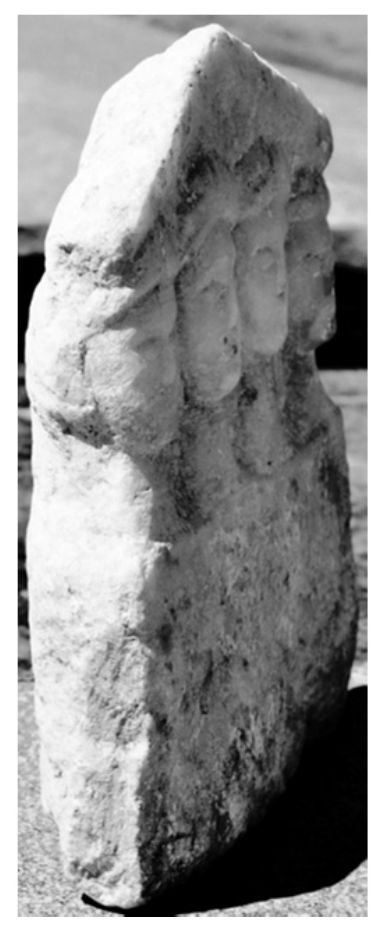

Figür 3 c

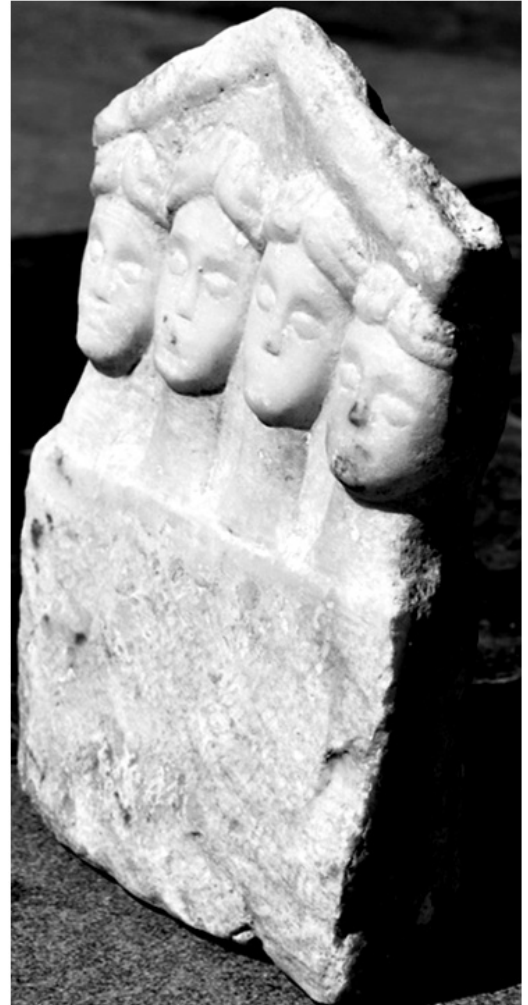

Figür 3 b

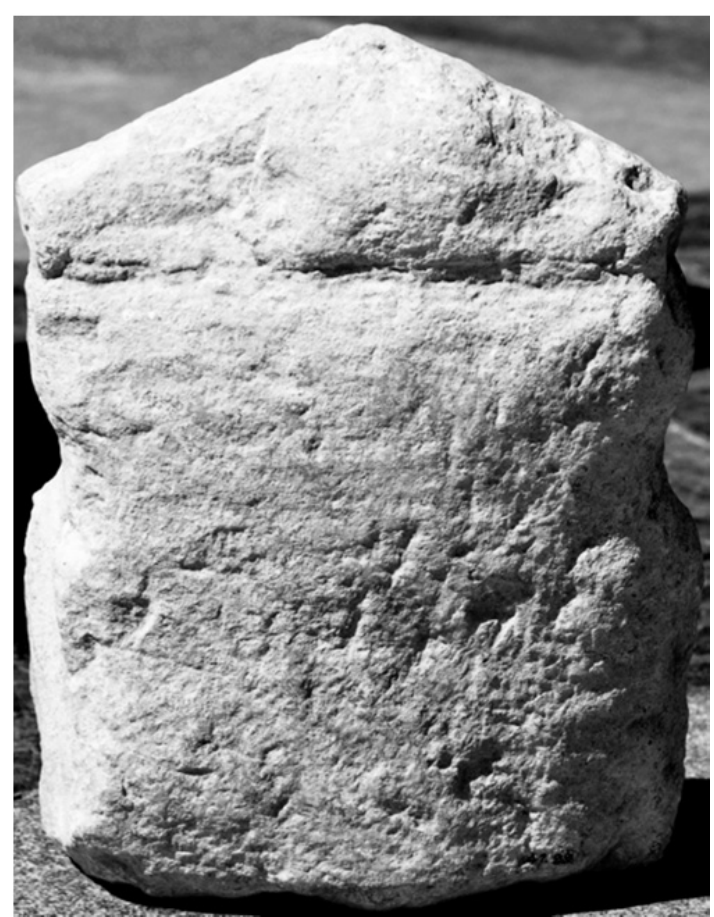

Figür 3 d 


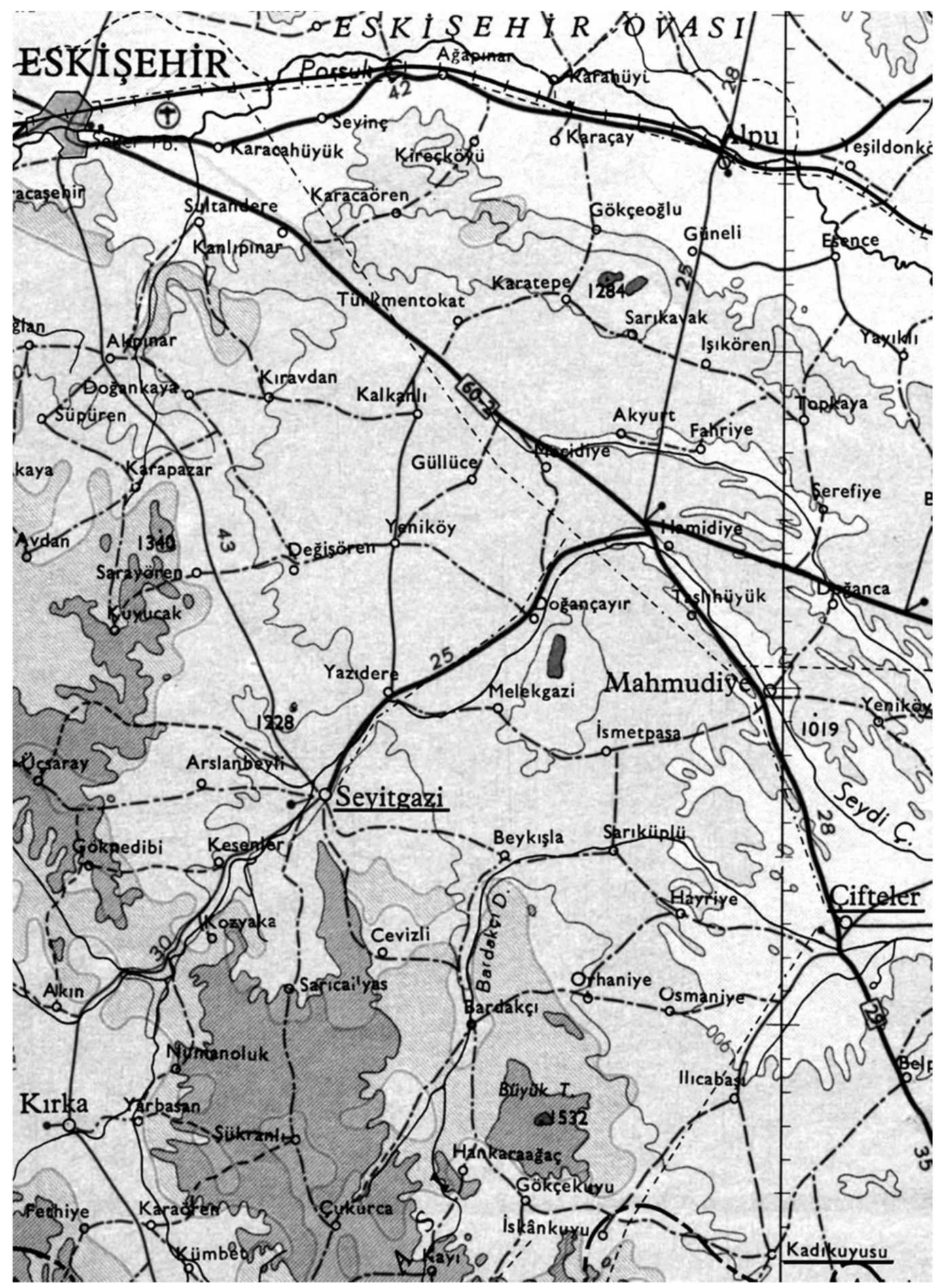

Harita: T.C. Harita Genel Müdürlüğü 1975, 1:500 000 Haritası, Eskişehir Paftası'ndan ayrıntı 
